\title{
Predictors of new oral anticoagulant drug initiation as opposed to warfarin in elderly adults: a retrospective observational study in Southern Italy
}

This article was published in the following Dove Press journal:

Therapeutics and Clinical Risk Management

\author{
Francesca Guerriero',* \\ Valentina Orlandol,* \\ Valeria Marina Monetti' \\ Francesca Maria Colaccio² \\ Maurizio Sessa ${ }^{3,4}$ \\ Cristina Scavone ${ }^{3}$ \\ Annalisa Capuano $3, *$ \\ Enrica Menditto',* \\ 'Center of Pharmacoeconomics \\ (CIRFF), University of Naples \\ Federico II, Naples, Italy; ${ }^{2}$ Caserta \\ Local Health Unit, Caserta, Italy; \\ ${ }^{3}$ Department of Experimental \\ Medicine, Section of Pharmacology, \\ Regional Center of Pharmacovigilance, \\ University of Campania "L.Vanvitelli", \\ Naples, Italy; ${ }^{4}$ Department of Drug \\ Design and Pharmacology, University \\ of Copenhagen, Copenhagen, DK, \\ Denmark \\ *These authors contributed equally \\ to this work
}

\begin{abstract}
Aim: The aim of this study was to assess the predictive role of age, gender, and number and type of co-treatments for new oral anticoagulant (NOAC) vs warfarin prescription in elderly patients naïve for the aforementioned drugs.

Materials and methods: Data collected in the period from January 1, 2014, to December 31, 2014, in Caserta Local Health Unit administrative databases (Campania Region, Italy) were screened to identify new users of oral anticoagulants (OACs) who were 75 years or older and whose OAC prescriptions amounted to $>90$ days of treatment. Age, gender, and number and type of concomitant medications at the time of first OAC dispensation were retrieved. Multivariable logistic regression analysis was used to assess the role of the aforementioned predictors for NOAC initiation as opposed to warfarin.

Results: Overall, 2,132 incident users of OAC were identified, of whom 967 met all inclusion criteria. In all, 490 subjects (50.7\%) received an NOAC and 477 (49.3\%) received warfarin. Age $>75$ years was positively associated with lower odds of NOAC initiation (OR: $0.969,95 \%$ CI: $0.941-0.998, P=0.038$ ). Similarly, multiple concomitant medication was negatively associated with NOAC initiation compared to warfarin (OR [five to nine drugs] group: $0.607,95 \% \mathrm{CI}$ : 0.432-0.852, $P=0.004$; OR [ten+ drugs] group: $0.372,95 \%$ CI: $0.244-0.567, P<0.001)$. Prior exposure to platelet aggregation inhibitor drugs was associated with the initiation of NOACs (OR: 3.474, 95\% CI: 2.610-4.625).
\end{abstract}

Conclusion: Age and multiple co-medication were negatively associated with NOAC initiation.

Keywords: retrospective databases, real-world data, atrial fibrillation, oral anticoagulation, drug utilization

\section{Introduction}

Atrial fibrillation (AF) is the most frequent cardiac arrhythmia, and its prevalence increased progressively with age. ${ }^{1-3}$ AF prevalence was estimated to be less than $0.1 \%$ in the population aged $<55$ years and rise to over $8 \%$ in those aged $>80$ years. ${ }^{4}$ Patients with AF have a fivefold higher risk of stroke, which increases with age, reaching $23.5 \%$ between 80 and 89 years of age. ${ }^{5}$ Vitamin $\mathrm{K}$ antagonists (VKAs) have been historically used to reduce cardiovascular risk associated with AF especially for stroke prophylaxis. ${ }^{6}$ However, recently, a new therapeutic alternative to VKA was introduced, the new oral anticoagulants (NOACs). NOACs include both direct thrombin inhibitors (dabigatran) and direct factor Xa inhibitors (rivaroxaban, apixaban, and edoxaban). Dabigatran and rivaroxaban were authorized by European Medicine Agency (EMA) in 2008 and became available on the Italian market in 2013.
Correspondence: Enrica Menditto CIRFF, Center of Pharmacoeconomics, University of Naples Federico II, Via Domenico Montesano 49, 80I3I Naples, Italy

Tel $+3908 \mid 1678660$

Fax +39 08। I678658

Email enrica.menditto@unina.it 
Apixaban was approved by EMA in 2011 and became available for use in clinical practice in Italy in January 2014, while edoxaban was the last NOAC that obtained the marketing authorization by EMA in June 2015. Initially, in 2010, the Italian Medicine Agency (Agenzia Italiana del Farmaco, AIFA) allowed the use of NOACs only for the prophylaxis of venous thromboembolism after hip replacement surgery and knee surgery. However, since 2013, AIFA has extended the authorization also for reducing cardiovascular risk in non-valvular AF. In terms of stroke and systemic thromboembolism prevention, dabigatran, apixaban, rivaroxaban, and edoxaban demonstrated at least non-inferiority to warfarin. ${ }^{7}$ Moreover, NOACs, when compared to VKA, provided a more reliable anticoagulation effect with a limited drug-drug and drug-food interactions, especially in frail population, such as elderly patients. ${ }^{8,9}$ Considering these advantages, European guidelines for the management of AF recommended the initiation of an NOAC instead of warfarin in non-valvular AF. ${ }^{7}$ However, to date, previous studies suggested that VKA tends to be underutilized especially in the elderly patients with AF. ${ }^{10}$ Considering that little is known on the widespread activity of NOACs as therapeutic alternative in patients with AF, and even less is known on the predictors leading to their choice in clinical practice, this study aimed to fill this gap by investigating the use of NOACs and predictors of its initiation, as opposed to warfarin, in elderly patients with AF.

\section{Materials and methods Data source}

Based on data availability, we retrieved anonymized data stored in Caserta Local Health Unit (LHU) administrative databases from January 1, 2014, to December 31, 2014. For reimbursement purposes, Caserta LHU administrative databases contain demographical information (ie, age, gender, and date of death), hospital contact, and drugs redeemed/ supplied from pharmacies/local health authority in the catchment area of Caserta (Campania Region, Italy) which covers a population of approximately 1 million inhabitants. For each redeemed/supplied prescription information on the active ingredient, dose, formulation, the number of packages, the date of dispensation, drug price, and the Anatomical Therapeutic Chemical (ATC) classification system code were available. ${ }^{11}$ In the aforementioned databases, all information was linked through a unique and anonymous personal identification code. These data sources have been previously used for pharmacoepidemiological and drug utilization study purposes. $^{12-19}$

\section{Study population}

The study population consisted of all subjects aged 75 years or older receiving at least one prescription of warfarin or NOAC in the period from January 1, 2014, to December 31, 2014. We defined a subject as receiving a warfarin prescription if he/she redeemed a prescription with a drug having ATC code B01AA03. On the other hand, we defined NOAC users as those subjects redeeming prescriptions of dabigatran (ATC code: B01AE07), rivaroxaban (ATC code: B01AF01), and apixaban (ATC code: B01AF02). The date of the first redemption of such prescriptions was used as the index date for each subject. From this preliminary population, we identified our study population that is composed of naïve users of warfarin or NOACs. We defined a subject as naïve for warfarin or NOACs if he/she did not redeem prescriptions of these drugs within 365 days prior to index date. Because information on the medical needs leading to a prescription of warfarin or NOACs was not available, to assume AF as the indication of use for such drugs, we restricted the analysis to subjects whose pharmacy prescriptions amounted to $\geq 90$ days of anticoagulation (90 or more days between first and last OAC prescription dates). Figure 1 shows the flowchart of the study.

\section{Study covariates}

For each subject, we retrieved information on age, gender, and co-treatment in the 12-month period prior to the index date. Specifically, we evaluated the number of co-prescribed medications within 365 days prior to index date and the exposure to specific co-treatments: drugs platelet aggregation inhibitor (PAI) excluding heparin (ATC: B01AC), anti-inflammatory and antirheumatic products (ATC: M01A), and proton pump inhibitor (PPI; ATC: A02B). Moreover, AF drugs such as digitalis glycosides (ATC: C01AA), antiarrhythmics class Ia (ATC: C01BA), antiarrhythmics class Ic (ATC: C01BC), antiarrhythmics class III (ATC: C01BD), strophanthus glycosides (ATC: C01AC), other cardiac glycosides (ATC: C01AX), nonselective beta-blocking agents (ATC: C07AA), selective beta-blocking agents (ATC: C07AB), and alpha and beta-blocking agents (ATC: C07AG) were also evaluated. Finally, selective serotonin reuptake inhibitor/serotonin norepinephrine reuptake inhibitor (SSRI/SNRI; ATC: N06A) was evaluated. The number of co-prescribed drugs was categorized as follows: $0-4$ drugs, $5-9$ drugs, and $\geq 10$ drugs.

\section{Outcomes}

The study outcomes are the OR of receiving an NOAC prescription as opposed to a warfarin prescription among 


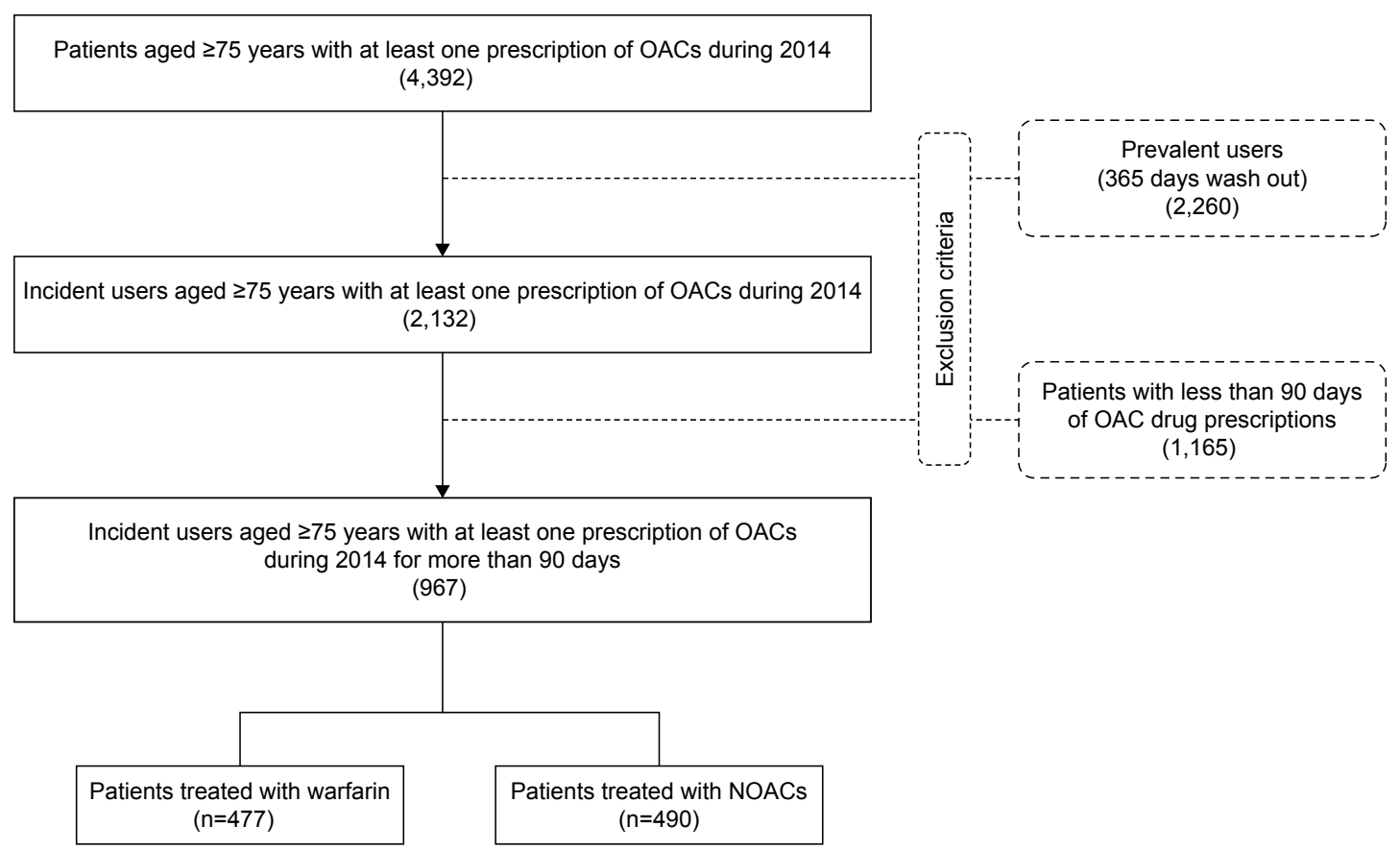

Figure I Patient selection flowchart.

Abbreviations: NOACs, new oral anticoagulants; OACs, oral anticoagulants.

genders, ages (expressed as unitary increase), and patients exposed to specific co-treatments.

\section{Statistical analysis}

Baseline characteristics of the study cohort were presented separately for NOACs and warfarin. Continuous variables were presented as mean $\pm \mathrm{SD}$, and differences between two therapy groups were compared using the Student's unpaired $t$-test. Categorical variables were presented as numbers (percentages) and were compared across therapy groups by chi-squared test. Univariate and multivariate logistic regression models were conducted to identify whether study covariates were predictors of NOAC initiation as opposed to warfarin. In the multivariate model, all the potential predictors were entered that were significant at the $P<0.25$ in the univariate analysis. All analyses were performed using SPSS software version 17.1 for Windows (IBM Corporation, Armonk, NY, USA). A $P$-value of $<0.05$ was considered as statistical significance.

\section{Results}

Overall, 4,392 subjects aged 75 years or older, with at least one prescription of OAC drugs, were identified from January 1, 2014, to December 31, 2014. Among these subjects, 967 out of 4,392 (22.01\%) were naïve and treated for at least 90 days with OACs (Figure 1). The characteristics of the study population are summarized in Table 1 . The mean age (SD) of the study population was 81.5 years (4.5 years), and the female gender $(61.4 \%)$ was predominant. In all, 490 (50.7\%) out of the 967 patients were exposed to NOACs and 477 (49.3\%) to warfarin. Among the 490 patients treated with NOACs, more than half (58.6\%) received rivaroxaban, $22.4 \%$ apixaban, and $19.0 \%$ dabigatran. A significantly lower number of subjects received PAI among warfarin users if compared to NOAC users $(P<0.001)$. The number of patients receiving AF drugs, NSAIDs, and SSRI/SNRI was comparable between patients exposed to NOAC therapy vs those exposed to warfarin. The number of co-prescribed drugs was comparable between NOAC and warfarin patients $(P=0.076)$.

\section{Predictors of NOAC initiation}

Increasing age was significantly associated with a lower odds of NOAC initiation: for each 1-year increase in age, patients were about 3\% less likely to receive an NOAC (OR: 0.969, 95\% CI: 0.941-0.998, $P=0.038$; Table 2 and Figure 2). As the number of co-prescribed medicines increased, an increased likelihood of receiving warfarin as opposed to NOACs was observed. In particular, subjects exposed to five to nine drugs and those exposed to ten+ drugs were $39 \%$ and $63 \%$ less likely to receive an NOAC (OR [five to nine drugs] group: 0.607, 95\% CI: $0.432-0.852, P=0.004$; OR [ten+ drugs] group: $0.372,95 \% \mathrm{CI}: 0.244-0.567, P<0.001)$. The strongest predictors of NOAC initiation were the previous exposure to 
Table I Descriptive statistics of the study population $(\mathrm{N}=967)$

\begin{tabular}{|c|c|c|c|c|}
\hline & NOACs $(n=490)$ & Warfarin $(n=477)$ & Overall $(\mathrm{N}=967)$ & $P$-value \\
\hline Gender (female) & 289 (59.0\%) & 305 (63.9\%) & $594(61.4 \%)$ & 0.113 \\
\hline Age $($ mean $\pm S D)$ & $81.3 \pm 4.5$ & $81.6 \pm 4.5$ & $81.5 \pm 4.5$ & 0.217 \\
\hline \multicolumn{4}{|l|}{ Age group } & \multirow[t]{4}{*}{0.517} \\
\hline 75-79 years & 193 (39.4\%) & $177(37.1 \%)$ & $370(38.3 \%)$ & \\
\hline 80-84 years & $176(35.9 \%)$ & $167(35.0 \%)$ & $343(35.5 \%)$ & \\
\hline $85+$ years & $12 \mid(24.7 \%)$ & I 33 (27.9\%) & $254(26.3 \%)$ & \\
\hline Receiving PAI & $273(55.7 \%)$ & $150(31.4 \%)$ & $423(43.7 \%)$ & $<0.00 I^{*}$ \\
\hline Receiving AF drugs & 378 (77.1\%) & $372(78.0 \%)$ & 750 (77.6\%) & 0.753 \\
\hline Receiving NSAIDs & $221(45.1 \%)$ & $220(46.1 \%)$ & $44 \mid(45.6 \%)$ & 0.750 \\
\hline Receiving J02A & $15(3.1 \%)$ & $13(2.7 \%)$ & $28(2.9 \%)$ & 0.755 \\
\hline Receiving PPI & 369 (75.3\%) & $367(76.9 \%)$ & $736(76.1 \%)$ & 0.552 \\
\hline Receiving SSRI/SNRI & $74(15.1 \%)$ & $72(15.1 \%)$ & $146(15.1 \%)$ & 0.997 \\
\hline \multicolumn{4}{|c|}{ Number of co-prescribed medicines } & \multirow[t]{4}{*}{0.076} \\
\hline $0-4$ & $118(24.1 \%)$ & $92(19.3 \%)$ & $210(21.7 \%)$ & \\
\hline $5-9$ & $272(55.5 \%)$ & $264(55.3 \%)$ & $536(55.4 \%)$ & \\
\hline $10-14$ & $100(20.4 \%)$ & $12 \mid(25.4 \%)$ & $221(22.9 \%)$ & \\
\hline
\end{tabular}

Note: *P-value of $<0.05$ was considered statistically significant.

Abbreviations: AF, atrial fibrillation; J02A, antimycotics for systemic use; NOACs, new oral anticoagulants; PAI, platelet aggregation inhibitor; PPI, proton pump inhibitor; SSRI/SNRI, selective serotonin reuptake inhibitor/serotonin norepinephrine reuptake inhibitor.

PAI which was three times more likely to use an NOAC as opposed to warfarin (OR: 3.474, 95\% CI: 2.610-4.625).

\section{Ethics statement}

All procedures performed in this study were in accordance with the current national law from Italian Medicines Agency. ${ }^{45}$ The manuscript does not contain clinical studies, and all patients' data were fully anonymized. For this type of study, formal consent is not required. Permission to use anonymized data for the present study was granted by the responsible authority, Caserta LHU, Regione Campania.

\section{Discussion}

This study provides up-to-date information on the recent anticoagulation prescription behavior in elderly patients with AF in the catchment area of Caserta (Campania Region, Italy). In this regard, it should be emphasized that stroke prophylaxis among high-risk patients, eg, elderly, is clinically challenging, and data show that OAC treatment is often underused. ${ }^{20,21}$ The suboptimal OAC treatment of elderly patients has been increasingly explored in recent years as elderly patients are at particularly high risk of stroke, and prior studies have shown that OAC provides a net clinical benefit among elderly AF patients. ${ }^{22,24}$ According to our findings, polypharmacy seems to drive the choice of VKA over NOAC. In fact, elderly patients with AF exposed to moderate polypharmacy (five to nine drugs) and extensive polypharmacy (ten+ drugs) were $39 \%$ and $63 \%$ less likely to receive an NOAC compared to warfarin users, respectively. This finding is in line with a retrospective study carried out in Ireland showing that

Table 2 Univariate and multivariate model predicting the initiation of NOACs vs warfarin

\begin{tabular}{|c|c|c|c|c|}
\hline Characteristics & Unadjusted OR $(95 \% \mathrm{CI})$ & $P$-value & Adjusted OR (95\% Cl) & $P$-value \\
\hline \multicolumn{5}{|l|}{ Sex } \\
\hline Male & Reference & & Reference & \\
\hline Female & $0.81 \mathrm{I}(0.626-1.05 \mathrm{I})$ & 0.113 & $0.830(0.631-1.090)$ & 0.180 \\
\hline Age (years) & $0.982(0.955-1.010)$ & 0.217 & $0.969(0.94 I-0.998)$ & $0.038 *$ \\
\hline \multicolumn{5}{|l|}{ Receiving PAI } \\
\hline No & Reference & & Reference & \\
\hline Yes & $0.365(0.280-0.474)$ & $<0.00 I^{*}$ & $3.474(2.610-4.625)$ & $<0.00 I^{*}$ \\
\hline \multicolumn{5}{|c|}{ Number of co-prescribed medicines } \\
\hline $0-4$ & Reference & & Reference & \\
\hline $5-9$ & $0.803(0.583-1.107)$ & 0.181 & $0.607(0.432-0.852)$ & $0.004^{*}$ \\
\hline $10+$ & $0.644(0.44 I-0.942)$ & $0.023^{*}$ & $0.372(0.244-0.567)$ & $<0.00 I^{*}$ \\
\hline
\end{tabular}

Notes: OR values higher than 1.0 indicate predictors of NOAC initiation as opposed to warfarin and vice versa. $*$-value of $<0.05$ was considered statistically significant. Abbreviations: NOACs, new oral anticoagulants; PAI, platelet aggregation inhibitor. 


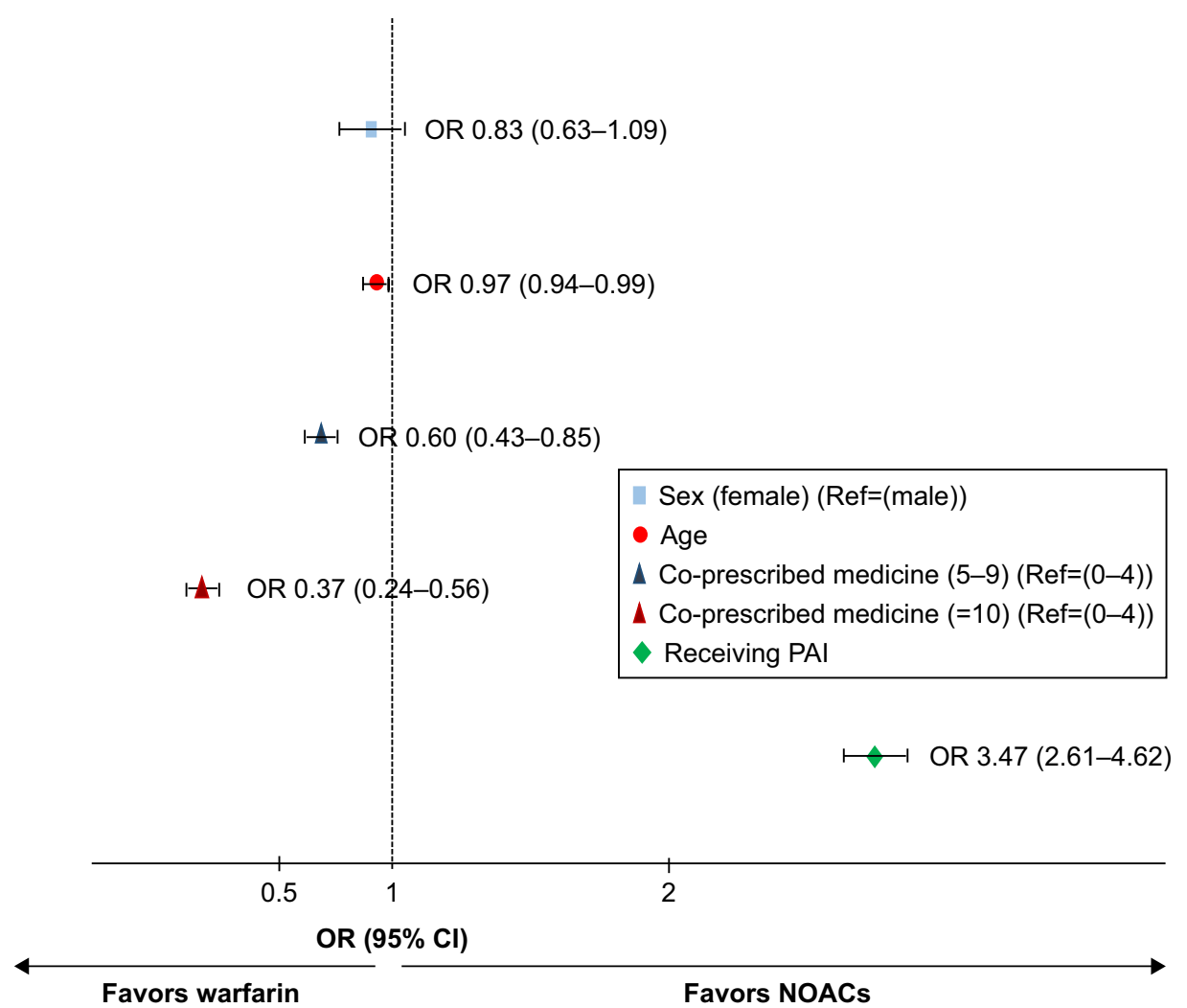

Figure 2 Forest plot of predictors of NOAC vs warfarin initiation.

Abbreviations: NOACs, new oral anticoagulants; PAl, platelet aggregation inhibitor; Ref, reference.

multiple concomitant medications were negatively associated with NOAC initiation. ${ }^{25}$ On the other hand, our findings are in contrast with other previous studies. Results of the study by Belen et al, ${ }^{26}$ which investigated the reasons for a decline in VKA utilization, revealed that potential drugdrug interactions (DDIs) and diet were the most common reasons for choosing NOAC over VKA. According to Belen et al, further literature data demonstrated that, especially for elderly patients, NOACs represent a more suitable treatment option compared to warfarin due to a more predictable dosing, fewer DDIs, and reduced risk of intracranial bleeding. ${ }^{27}$ In addition, a study by AbuDagga et $\mathrm{a}^{28}$ reported that older age decreased the probability of initiating dabigatran, but their study ended in 2014, and rivaroxaban and apixaban data were absent. Nevertheless, our results showed that VKA treatment is still used and, in contrast to the NOACs, VKAs have the advantage of being suitable for patients with severe renal impairment (creatinine clearance $\leq 15 \mathrm{~mL}$ / min). ${ }^{22}$ Still, a lack of knowledge on NOACs' DDIs may limit their tangible use, especially in elderly patients. As a matter of fact, despite their advantages over warfarin, NOACs carry a potential for DDIs, which could occur more frequently in elderly than in younger patients, due to the age-related higher prevalence of comorbidities and polymedication. ${ }^{29}$ A recent review by Stöllberger ${ }^{30}$ highlighted that several drugs, including acetylsalicylic acid, clopidogrel, ticagrelor, prasugrel, NSAIDs, and SSRIs/SNRIs, could interact with NOACs, increasing the risk of bleeding complications. Moreover, since NOACs are metabolized by the CYP/CYP450 isoenzymes 3A4 (CYP3A4) and 2J9 (CYP2J9), DDIs were also identified with drugs that affect the activity of such cytochrome isoenzymes. Furthermore, considering that NOACs are substrates for the drug ellux pump, P-glycoprotein (P-gp),drugs affecting the activity of P-gp, such as atorvastatin, clarithromycin, and diltiazem, can increase the risk of bleeding, thromboembolism, and further adverse events. Finally, it was found out that NOACs could influence the serum and tissue concentrations of immunosuppressant and analgesic drugs as well as that PPIs may affect NOAC bioavailability changing the gastric $\mathrm{pH}$. A recent retrospective cohort study, which has evaluated, on more than 90,000 patients, the effects on major bleedings of co-exposure to NOACs and other drugs, revealed that the concurrent use of NOACs and amiodarone, fluconazole, rifampin, and phenytoin was associated with the increased risk of the main outcome. ${ }^{31}$ However, considering that few 
data from clinical practice are nowadays available on this topic, further data are strongly needed. Another interesting finding of our study is that the factor most strongly associated with NOAC initiation was the previous PAI utilization. In particular, patients receiving PAI medication were more than three times as likely to use an NOAC compared to warfarin (OR: 3.474, 95\% CI: 2.610-4.625). These results could be explained considering that the concomitant use of PAI and OACs, also known as triple oral antithrombotic therapy (TOAT), is required in the specific group of patients affected by cardiovascular disease, usually AF which had drug-eluting stent implantation or acute coronary syndrome. ${ }^{32}$ Therefore, in our opinion, the higher probability for patients receiving PAI medication to initiate an NOAC could be related to the easier management of therapy with NOAC compared to warfarin especially in terms of its bleeding risk. In our cohort, more than $50 \%$ of patients received a prescription of rivaroxaban, $22 \%$ of elderly patients were on apixaban, while dabigatran was adopted in about $19 \%$ of elderly patients. In this regard, we do not believe that this result could be associated with the different efficacy/safety differences among NOACs. In fact, the pivotal study for rivaroxaban, the multicenter, randomized, double-blind, double-dummy ROCKET AF trial, which compared once-daily oral rivaroxaban with dose-adjusted warfarin for the prevention of stroke and systemic embolism in patients with nonvascular AF who were at moderate to high risk for stroke, revealed that rivaroxaban was non-inferior to warfarin, with an annual rate of stroke and systemic embolism $2.12 \%$ vs $2.42 \%(P<0.001)$ reported with warfarin. ${ }^{7}$ Safety results demonstrated that rivaroxaban was associated with a significant reduction in fatal bleeding $(0.2 \%$ vs $0.5 \%$ per year, $P=0.003)$ and cerebral hemorrhage $(0.5 \%$ vs $0.7 \%$ per year, $P=0.02)$. Since rivaroxaban is, for one-third, renally cleared, it is especially safe in patients with mild renal impairment (creatinine clearance $30-49 \mathrm{~mL} / \mathrm{min}$ ), which is one of the most frequent comorbidities in the elderly. ${ }^{33}$ Similarly, the results of ARISTOTLE trial and its post hoc analyses found that apixaban had a lower relative risk of stroke or systemic embolism as well as major bleeding and death when compared to warfarin. ${ }^{34,35}$ Moreover, a recent review by Diener et $\mathrm{l}^{36}$ suggested apixaban as the first choice in AF patients older than 75 years. Although no comparable head-to-head randomized trial has examined the efficacy and safety between the NOACs yet, it is likely that the positive results from the ARISTOTLE trial might have influenced the rapidly increased uptake of apixaban compared to the other NOACs, in particular among elderly AF patients. ${ }^{37}$ Finally, dabigatran was also associated with a notably lower relative risk of stroke or systemic embolism compared to warfarin, although it was related to an increased risk of gastrointestinal bleedings. ${ }^{38}$ Notably, approximately $80 \%$ of dabigatran is eliminated by renal clearance, and a condition with impaired renal function is often found among elderly patients. ${ }^{39}$ Data from the RE-LY trial showed that renal function was highly correlated with age, and plasma concentration of dabigatran increased with advancing age. ${ }^{40}$

Local policies should provide training and information to health care professionals to optimize health resources also implementing successful elements from other EU countries' activities. ${ }^{41,42}$ Synergies between different actors involved in health care delivery can help achieve better results. Further studies are needed to improve our knowledge of the safety profile in a real-world setting.

\section{Strengths and limitations}

The main strength of our study is based on a data source with full coverage of the warfarin and NOAC prescriptions for a geographically defined, stable population, and we were able to account for multiple confounders such as age, gender, and co-medications. ${ }^{10}$ However, the study also has potential limitations. Some predictive factors, such as comorbidities or previous cardiovascular events, have not been considered. Furthermore, as VKA administration may increase arterial stiffness (which is a predictor of cardiovascular risk), lack of information about diagnosis and stroke occurrence did not allow us to evaluate the advantage of NOAC use vs warfarin. Data reported in the study refer to 2014, and the current patterns regarding the use of NOACs could have changed meanwhile. Finally, doses of NOACs used have not been reported: further studies should be carried out for evaluating dosing regimens used in the real practice as reduced doses could be inappropriate and ineffective.

\section{Conclusion}

This study provides data on prescription of NOACs and warfarin from clinical practice in the Italian national territory. In a real-world setting, multiple co-medication may be associated with lower likelihood of NOAC initiation. This trend is more evident in patients with excessive polypharmacy (more than ten drugs) bringing significant implications for cost-effectiveness and outcome studies.

\section{Acknowledgments}

This study is part of a set of initiatives to promote the appropriate drug use and drug safety in Campania Region. ${ }^{43-60}$ This study was supported by grants from the Regional Funding on Pharmacovigilance of the Campania Region (Progetto per 
la valutazione e 1'analisi della prescrizione farmaceutica in Regione Campania).

\section{Disclosure}

The authors report no conflicts of interest in this work.

\section{References}

1. Go AS, Hylek EM, Phillips KA, et al. Prevalence of diagnosed atrial fibrillation in adults: national implications for rhythm management and stroke prevention: the AnTicoagulation and Risk Factors in Atrial Fibrillation (ATRIA) Study. JAMA. 2001;285(18):2370-2375.

2. Miyasaka Y, Barnes ME, Gersh BJ, et al. Secular trends in incidence of atrial fibrillation in Olmsted County, Minnesota, 1980 to 2000, and implications on the projections for future prevalence. Circulation. 2016;114(2):119-125.

3. Naccarelli GV, Varker H, Lin J, Schulman KL. Increasing prevalence of atrial fibrillation and flutter in the United States. Am J Cardiol. 2009;104(11):1534-1539.

4. Fuster V, Ryde'n LE, Cannom DS, et al. American College of Cardiology/American Heart Association Task Force on Practice Guidelines; European Society of Cardiology Committee for Practice Guidelines; European Heart Rhythm Association; Heart Rhythm Society. ACC/AHA/ESC Guidelines for the Management of Patients with Atrial Fibrillation: a report of the American College of Cardiology/ American Heart Association Task Force on Practice Guidelines and the European Society of Cardiology Committee for Practice Guidelines (Writing Committee to Revise the 2001 Guidelines for the Management of Patients With Atrial Fibrillation): developed in collaboration with the European Heart 520 JABFM July-August 2015 Vol. 28 No. 4. Rhythm Association and the Heart Rhythm Society. Circulation. 2006;114:e257-e354. http://www.jabfm.org

5. Wolf PA, Abbott RD, Kannel WB. Atrial fibrillation as an independent risk factor for stroke: the Framingham Study. Stroke. 1991;22(8):983-988.

6. Wilke T, Bauer S, Mueller S, Kohlmann T, Bauersachs R. Patient Preferences for Oral Anticoagulation Therapy in Atrial Fibrillation: A Systematic Literature Review. Patient. 2017;10(1):17-37.

7. Camm AJ, Lip GY, De Caterina R, et al. 2012 focused update of the ESC guidelines for the management of atrial fibrillation: an update of the 2010 ESC guidelines for the management of atrial fibrillation developed with the special contribution of the European Heart Rhythm Association. Eur Heart J. 2012;33(21):2719-2747.

8. di Minno MN, Russolillo A, di Minno A, Camera M, Parolari A, Tremoli E. Direct anticoagulant drugs to overcome limitations of vitamin K antagonists. A critical appraisal of data in atrial fibrillation patients. Expert Opin Emerg Drugs. 2013;18(1):9-23.

9. Safavi-Naeini P, Saeed M. Target-specific oral anticoagulants: should we switch from warfarin? Tex Heart Inst J. 2015;42(3):229-233.

10. Ng KH, Hart RG, Eikelboom JW. Anticoagulation in Patients Aged $\geq 75$ years with Atrial Fibrillation: Role of Novel Oral Anticoagulants. Cardiol Ther. 2013;2(2):135-149.

11. World Health Organization Collaborating Centre for Drug Statistics Methodology. Available from: https://www.whocc.no/atc_ddd_index/. Accessed May, 2018.

12. Iolascon G, Gimigliano F, Moretti A, et al. Rates and reasons for lack of persistence with anti-osteoporotic drugs: analysis of the Campania region database. Clin Cases Miner Bone Metab. 2016;13(2):127-130.

13. Iolascon G, Gimigliano F, Orlando V, Capaldo A, di Somma C, Menditto E. Osteoporosis drugs in real-world clinical practice: an analysis of persistence. Aging Clin Exp Res. 2013;25 Suppl 1(1):137-141.

14. Orlando V, Guerriero F, Putignano D, et al. Prescription Patterns of Antidiabetic Treatment in the Elderly. Results from Southern Italy. Curr Diabetes Rev. 2015;12(2):100-106.

15. Comella P, Franco L, Casaretti R, de Portu S, Menditto E. Emerging role of capecitabine in gastric cancer. Pharmacotherapy. 2009;29(3):318-330.
16. Menditto E, Guerriero F, Orlando V, et al. Self-Assessment of Adherence to Medication: A Case Study in Campania Region CommunityDwelling Population. J Aging Res. 2015;2015:682503.

17. Guerriero F, Orlando V, Monetti VM, Russo V, Colaccio F, Menditto E. Biologic therapy utilization, switching and cost among patients with psoriasis: retrospective analysis of administrative databases in Southern Italy. Clinicoecon Outcomes Res. 2017;9:741-748.

18. Menditto E, Orlando V, Coretti S, Putignano D, Fiorentino D, Ruggeri M. Doctors commitment and long-term effectiveness for cost containment policies: lesson learned from biosimilar drugs. Clinicoecon Outcomes Res. 2015;7:575-581.

19. Russo V, Monetti VM, Guerriero F, et al. Prevalence of antibiotic prescription in southern Italian outpatients: real-world data analysis of socioeconomic and sociodemographic variables at a municipality level. Clinicoecon Outcomes Res. 2018;10:251-258.

20. Bungard TJ, Ghali WA, Teo KK, Mcalister FA, Tsuyuki RT. Why do patients with atrial fibrillation not receive warfarin? Arch Intern Med. 2000;160(1):41-46.

21. Tulner LR, van Campen JP, Kuper IM, et al. Reasons for undertreatment with oral anticoagulants in frail geriatric outpatients with atrial fibrillation: a prospective, descriptive study. Drugs Aging. 2010;27(1): 39-50.

22. Andreotti F, Rocca B, Husted S, et al. Antithrombotic therapy in the elderly: expert position paper of the European Society of Cardiology Working Group on Thrombosis. Eur. Heart J. 2015:ehv304.

23. Schnabel RB, Yin X, Gona P, et al. 50 year trends in atrial fibrillation prevalence, incidence, risk factors, and mortality in the Framingham Heart Study: a cohort study. Lancet. 2015;386(9989):154-162.

24. Lip GY, Lane DA. Stroke prevention with oral anticoagulation therapy in patients with atrial fibrillation - focus on the elderly. Circ J. 2013;77(6):1380-1388.

25. Spillane S, Bennett K, Barry M. Initiation of Oral Anticoagulant Drugs: Identification of Drivers of Prescribing of New Agents Versus Warfarin. Value Health. 2014;17(7):A 499-500.

26. Belen E, Canbolat IP, Bayyigit A, et al. A new gap in the novel anticoagulants' era: undertreatment. Blood Coagul Fibrinolysis. 2015;26(7):793-797.

27. Hanley CM, Kowey PR. Are the novel anticoagulants better than warfarin for patients with atrial fibrillation? J Thorac Dis. 2015;7(2): $165-171$.

28. AbuDagga A, Stephenson JJ, Fu AC, Kwong WJ, Tan H, Weintraub WS. Characteristics affecting oral anticoagulant therapy choice among patients with non-valvular atrial fibrillation: a retrospective claims analysis. BMC Health Serv Res. 2014;14:310.

29. Trikha R, Kowey PR. Practical Considerations for the Nonvitamin K Antagonist Oral Anticoagulants. Cardiology. 2017;136(2):115-124. Epub 2016 Sep 6.

30. Stöllberger C. Drug interactions with new oral anticoagulants in elderly patients. Expert Rev Clin Pharmacol. 2017;10(11):1191-1202 Review. Epub 2017 Aug 28.

31. Chang SH, Chou IJ, Yeh YH, et al. Association Between Use of Non-Vitamin K Oral Anticoagulants With and Without Concurrent Medications and Risk of Major Bleeding in Nonvalvular Atrial Fibrillation. JAMA. 2017;318(13):1250-1259.

32. Lip GY, Windecker S, Huber K, et al. Management of antithrombotic therapy in atrial fibrillation patients presenting with acute coronary syndrome and/or undergoing percutaneous coronary or valve interventions: a joint consensus document of the European Society of Cardiology Working Group on Thrombosis, European Heart Rhythm Association (EHRA. European Association of Percutaneous Cardiovascular Interventions (EAPCI) and European Association of Acute Cardiac Care (ACCA) endorsed by the Heart Rhythm Society (HRS) and Asia-Pacific Heart Rhythm Society (APHRS) Eur Heart J. 2014;35:3155-3179.

33. Fox KA, Piccini JP, Wojdyla D, et al. Prevention of stroke and systemic embolism with rivaroxaban compared with warfarin in patients with non-valvular atrial fibrillation and moderate renal impairment. Eur Heart J. 2011;32(19):ehr342. 
34. Granger CB, Alexander JH, Mcmurray JJ, et al. Apixaban versus warfarin in patients with atrial fibrillation. $N$ Engl J Med. 2011;365(11): 981-992.

35. Halvorsen S, Atar D, Yang H, et al. Efficacy and safety of apixaban compared with warfarin according to age for stroke prevention in atrial fibrillation: observations from the ARISTOTLE trial. Eur Heart J. 2014;35(28): 1864-1872.

36. Diener HC, Aisenberg J, Ansell J, et al. Choosing a particular oral anticoagulant and dose for stroke prevention in individual patients with nonvalvular atrial fibrillation: part 1. Eur Heart J. 2017;38(12):852-859.

37. Jaspers Focks J, Brouwer MA, Wojdyla DM, et al. Polypharmacy and effects of apixaban versus warfarin in patients with atrial fibrillation: post hoc analysis of the ARISTOTLE trial. BMJ. 2016;353:i2868.

38. Connolly SJ, Ezekowitz MD, Yusuf S, et al. Dabigatran versus warfarin in patients with atrial fibrillation. $N$ Engl J Med. 2009;361(12): 1139-1151.

39. Reilly PA, Lehr T, Haertter S, et al. The effect of dabigatran plasma concentrations and patient characteristics on the frequency of ischemic stroke and major bleeding in atrial fibrillation patients: the RE-LY Trial (Randomized Evaluation of Long-Term Anticoagulation Therapy. J Am Coll Cardiol. 2014;63(4):321-328.

40. Violi F, Pastori D, Pignatelli P. Mechanisms and management of thrombo-embolism in atrial fibrillation. Journal of Atrial Fibrillation. Circulation. 2014;7(3):1112.

41. Illario M, Vollenbroek-Hutten M, Molloy DW, Menditto E, Iaccarino G, Eklund P. Active and Healthy Ageing and Independent Living. J Aging Res. 2015;2015:542183-3.

42. Illario M, Vollenbroek-Hutten MM, Molloy DW, Menditto E, Iaccarino G, Eklund P. Active and Healthy Ageing and Independent Living 2016. J Aging Res. 2016;2016:8062079. Epub 2016 Oct 12.

43. Mozos I, Stoian D, Luca CT. Crosstalk between Vitamins A, B12, D, K, C, and E Status and Arterial Stiffness. Dis Markers. 2017;2017: 8784971-14.

44. Namba S, Yamaoka-Tojo M, Kakizaki R, et al. Effects on bone metabolism markers and arterial stiffness by switching to rivaroxaban from warfarin in patients with atrial fibrillation. Heart Vessels. 2017;32(8):977-982.

45. Ministry of Health, Italian Medicines Agency. Circolare AIFA del 3 agosto; 2007. Available from: http://xoomer.virgilio.it/pgiuff/osservazionali.pdf. Accessed March 31, 2017.

46. Cammarota S, Bruzzese D, Sarnelli G, et al. Proton pump inhibitors prescribing following the introduction of generic drugs. Eur J Clin Invest. 2012;42(10):1068-1078.

47. Cammarota S, Falconio LM, Bruzzese D, et al. Lower rate of cardiovascular complications in patients on bolus insulin analogues: a retrospective population-based cohort study. PLoS One. 2013;8(11):e79762.

48. Scala D, Menditto E, Caruso G, et al. Are you more concerned about or relieved by medicines? An explorative randomized study of the impact of telephone counseling by pharmacists on patients' beliefs regarding medicines and blood pressure control. Patient Educ Couns. 2017;101(4):679-686.
49. Putignano D, Bruzzese D, Orlando V, Fiorentino D, Tettamanti A, Menditto E. Differences in drug use between men and women: an Italian cross sectional study. BMC Womens Health. 2017;17(1):73.

50. Scala D, Menditto E, Armellino MF, et al. Italian translation and cultural adaptation of the communication assessment tool in an outpatient surgical clinic. BMC Health Serv Res. 2016;101(4):679-686.

51. Coretti S, Romano F, Orlando V, et al. Economic evaluation of screening programs for hepatitis $\mathrm{C}$ virus infection: evidence from literature. Risk Manag Healthc Policy. 2015;8:45-54.

52. Sessa M, Rossi C, Mascolo A, et al. Suspected adverse reactions to contrast media in Campania Region (Italy): Results from 14 years of postmarketing surveillance. Expert Opin Drug Saf. 2015;14:1341-1351.

53. Sessa M, Rafaniello C, Sportiello L, et al. Campania Region (Italy) spontaneous reporting system and preventability assessment through a case-by-case approach: a pilot study on psychotropic drugs. Expert Opin Drug Saf. 2016;15:9-15.

54. Mascolo A, Sessa M, Scavone C, et al. New and old roles of the peripheral and brain renin-angiotensin-aldosterone system (RAAS): Focus on cardiovascular and neurological diseases. Int J Cardiol. 2017;227: 734-742.

55. Mascolo A, Scavone C, Sessa M, et al. Can causality assessment fulfill the new European definition of adverse drug reaction? A review of methods used in spontaneous reporting. Pharmacol Res. 2017; 123:122-129.

56. Sessa M, Mascolo A, Andersen MP, et al. Effect of Chronic Kidney Diseases on Mortality among Digoxin Users Treated for Non-Valvular Atrial Fibrillation: A Nationwide Register-Based Retrospective Cohort Study. PLoS One. 2016;11:e0160337.

57. Rafaniello C, Ferrajolo C, Sullo MG, et al. Risk of gastrointestinal complications associated to NSAIDs, low-dose aspirin and their combinations: Results of a pharmacovigilance reporting system. Pharmacol Res. 2016;104:108-114.

58. Sessa M, Rossi C, Rafaniello C, et al. Campania preventability assessment committee: a focus on the preventability of the contrast media adverse drug reactions. Expert Opin Drug Saf. 2016;15:51-59.

59. Scavone C, Sportiello L, Sullo MG, et al. Safety Profile of Anticancer and Immune-Modulating Biotech Drugs Used in a Real World Setting in Campania Region (Italy): BIO-Cam Observational Study. Front Pharmacol. 2017;8:607. http://journal.frontiersin.org/article/

60. Sessa M, Mascolo A, Mortensen RN, et al. Relationship between heart failure, concurrent chronic obstructive pulmonary disease and beta-blocker use: a Danish nationwide cohort study. Eur J Heart Fail. 2018;20(3):548-556.
Therapeutics and Clinical Risk Management

\section{Publish your work in this journal}

Therapeutics and Clinical Risk Management is an international, peerreviewed journal of clinical therapeutics and risk management, focusing on concise rapid reporting of clinical studies in all therapeutic areas, outcomes, safety, and programs for the effective, safe, and sustained use of medicines. This journal is indexed on PubMed Central, CAS,

\section{Dovepress}

EMBase, Scopus and the Elsevier Bibliographic databases. The manuscript management system is completely online and includes a very quick and fair peer-review system, which is all easy to use. Visit http://www.dovepress.com/testimonials.php to read real quotes from published authors. 